\title{
IMAGE
}

\section{Complete pancreatic lipomatosis}

A 43-year-old woman presented with vague upper abdominal pain for last two months. She undergone had total mastectomy and axillary clearance for infiltrating ductal carcinoma 4 years back. She was on adjuvant therapy (tamoxifen $20 \mathrm{mg}$ OD). Physical examination did not reveal any organomegaly or palpable abdominal mass. Contrast enhanced computed tomography scan (CT scan) revealed (Fig. 1) uniform complete replacement of pancreas by fat. No intrapancreatic mass, calcification or pancreatic ductal dilatation was seen.

Pancreatic lipomatosis is an uncommon entity, seen as fatty infiltration or replacement of part or whole of the pancreas. It is reported to be associated with elderly age, obesity and diseases like diabetes mellitus, steroid therapy, Cushing disease, hereditary and chronic pancreatitis, hemochromatosis, malnutrition, congenital abnormalities such as cystic fibrosis and Shwachman-Diamond, obstruction of pancreatic duct by calculus or tumor, and viral infections. ${ }^{1,2}$ No such association was however present in our case.

Clinical symptoms of pancreatic lipomatosis depend upon degree of fatty replacement. Patients are usually asymptomatic with small focal fatty replacement but may present with atypical abdominal pain, and/or steatorrhea, mass effect of pancreas on the duodenal loop, or malabsorption with severe fatty replacement. ${ }^{1,2}$

$$
\begin{aligned}
& \text { Kushaljit Singh Sodhi } \cdot \text { Sameer Vyas } \cdot \text { N. Khandelwa }{ }^{1} \text {. } \\
& \text { Rajesh Gupta }{ }^{1}
\end{aligned}
$$

Departments of Radiodiagnosis and ${ }^{1}$ Surgery, Postgraduate Institute of Medical Education and Research, Chandigarh 160 012, India

\section{References}

1. Lin WC, Chen JH, Lin CH, Shen WC. Rapidly progressive pancreatic lipomatosis in a young adult patient with transfusion dependent myelodysplastic syndrome. J Formos Med Assoc 2007;106:676-9.

2. Kim KH, Kim CD, Ryu HS, et al. Endoscopic retrograde pancreatographic findings of pancreatic lipomatosis. $J$ Korean Med Sci 1999;14:578-81.

K. S. Sodhi $(\bowtie)$ e-mail: sodhiks@gmail.com

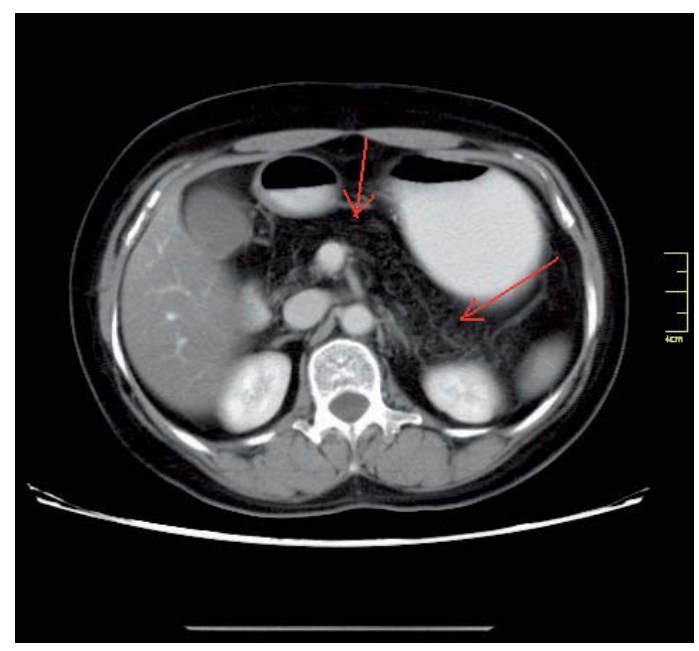

Fig. 1 CT scan reveals complete fatty replacement of the pancreas; arrows point to pancreatic body and tail region 